\title{
Introduction of Student Teachers in Tunisian Secondary Schools: A Discourse Analysis of Cooperative Teacher
}

\author{
Wadii Zayed ${ }^{1,2}$, Naila Bali1,2 \\ ${ }^{1}$ High Institute of Sport and Physical Education, Ksar Saîd, University la Manouba, Tunis, Tunisia \\ 2Tunisian Research Laboratory "Sport Performance Optimization", Tunis, Tunisia \\ Email: Zayed-wadii@hotmail.com, naila.bali@laposet.net
}

Received 22 February 2015; accepted 12 March 2015; published 16 March 2015

Copyright (C) 2015 by authors and Scientific Research Publishing Inc.

This work is licensed under the Creative Commons Attribution International License (CC BY). http://creativecommons.org/licenses/by/4.0/

(c) (i) Open Access

\begin{abstract}
In reference to professional training for trainee teachers, the tutor or cooperative teacher (CT) is considered as an alternation between two environments, academia and training, contributing to the training by the advice and support. Our research provides "support for physical education student teachers (PE-STs)" as determinants of teaching advice of CT. This study includes a qualitative analysis which aims to identify the advice of CTs to the student teachers for whom they are responsible for training. It's a descriptive/exploratory methodology based on observation and video recorded six (6) physical education (PE) sessions lasting one hour each and six semi structured interviews (30 minutes each) and gave CTs the opportunity to share their perspectives on broad topics such as professional training, teaching, and characteristics of the training environment and succinct topics such as training program and their preoccupation. Data were collected during 2 months of observations and interviews with six CTs during professional training of 12 PE-STs in Level 3 (third year, BAC+3). CTs justify their teaching by six categories in which we have grouped the different types of advice. The CTs are more interested by problems of organization and control students. They believe that educational content is worthless without a good control of the class.
\end{abstract}

\section{Keywords}

Professional Training, Student Teachers, Tutor, Accompanying

\section{Introduction}

The analysis of the tutorial activity by professionals has been a growing interest both in the training area in the

How to cite this paper: Zayed, W., \& Bali, N. (2015). Introduction of Student Teachers in Tunisian Secondary Schools: A Discourse Analysis of Cooperative Teacher. Creative Education, 6, 359-368. http://dx.doi.org/10.4236/ce.2015.63034 
work (Dugal, 2003; Carlier \& Clerx, 2012) and of High Institute of Sport and Physical Education (ISSEP) in Tunis (Bali \& Zayed, 2014). This interest is likely that the tutorial activity plays a joint role development of professional skills of trainee teachers (Darnis \& Magendie, 2011). According to Maela (2009) the term tutoring designs a defender, a protector and a guardian. It also inherits all practical accompanying an insertion referred to the professional life. Tutoring is situated at the crossroads of two logical productive and educational, and defined as training device in the workplace. Indeed, much research has demonstrated the importance of the accompaniment of the PE-ST on their practicum. In this context, the CT plays a fundamental role in facilitating their integration in the professional context (Lévesque \& Gervais, 2000; Martineau, 2003; Perez-Roux, 2012). However, Carlier (2000); Crinon (2003); Trohel et al. (2004) discussed the importance of exchange of scholarly knowledge, say that the CT would teach as it was taught and it's mainly based on his professional experience and teaching skills. Other research has provided contrasted results about the use the experience that is not enough to undertake the tasks of the trainer. Brau-Antony et al. (2011) report that tutoring is a difficult task. The CT share their professional time between a main teaching activity and a training PE-ST in practicum. According to Desbiens (2009) and Bali (2012, 2014), there is considerable uncertainty as to the qualification, experience and skills required to be a CT. The objective of this study is to highlight the teaching practices of CT. we will define a first time to study the nature of post sessions speeches at welcome sessions and check in a second time to identify the opinions in a confrontational data collected across data crossing observations and semi-directive interviews.

What is learned in the "welcome session the trainee"? I will be interested in this question in the field of the introduction of the PE-ST in Tunisian secondary schools. In order to operationalize research questions, we have developed the following hypothesis: The discourse of the CT help the PE-ST to integrate in to the professional life and establishing a good relationship. The organization and the mastery of students occupy the great part of advice and support of the CT.

\section{Methodology}

\subsection{Participants}

To test our research hypotheses, we used a sample consisting of 06 CT from two secondary schools in the Tunis region very engaged in professional training. These teachers are training everyone two trainees teachers. The CT has professional experience about 12 years and experience in the formation of the PE-ES between 5 and 10 years. Each CT is filmed during his speech in "natural" situation. These teachers are training everyone two PE-ST (Table 1).

Three main reasons justified the choice of this sample: 1) an institutional reason: This study is part of the professional training of student teachers. The CT is considered a person of alternating between the university and the training environment. This justifies the choice of the masters of this course is dual affiliation will allow us to see the nature of that advice of CT. 2) a social reason: there is a social difference between the academic and professional. This allowed us to hypothesize the role of CT in the integration of PE-ST. This difference could influence the teaching practices of student teachers. And 3) an academic reason: the application of the aims and the official program of physical education. Enabled to us hypothesize of the nature of the post-session speech of CT should accord with its orientations and promote student learning. To maximize opportunities to cover teachers trainers intervention, we asked all teachers working in/at ISSEP to participate in this study. Our work sample meets these three parameters as indicated in the Table 1 below. The criteria for selection of training environments are the number and distribution of PE-STs.

\begin{tabular}{cc} 
Table 1. Sample of Tunisian CT. \\
\hline Filmed & CT \\
\hline Interviewed & 06 \\
Filmed and interviewed & 06 \\
Years of Experience & $\geq 12$ years \\
Years of tutorat practice & Between 5 and 10 years
\end{tabular}




\subsection{The Interview Audio Post-Session}

Two week after the video recording sessions observing teaching discourse of CT, a semi structured interview was conducted with each of CT observed and recorded. This interview was conducted with six CT working in Tunis. We then proceeded to the transcription of audio recordings of semi-structured interviews individually established after the observation of each CT to form the PE-STs and we have reported in the grid also developed by the researcher (step 1). This grid has allowed us to categorize the discourse of CT. Finally, the third step is the linking of analyzes from different investigative techniques. We crossed the data collected during the first two steps. This categorization allowed us to approach through what the CT said and done.

\subsection{The Formation of the Corpus}

Structured interviews: we used a dictaphone to record the responses of CT interviewed. The questions focus on teaching council previously filmed subjects interviewed in the first meeting with the PE-STs. Then the CT are interviewed while allowing them freedom of speech they can express themselves at their ease. Accordance with the principles of the semi structured interview (Mucchielli, 1979, 1983), the interview guide may change due to data collected by the observations of CT council in these subjects interviewed but without deviating from the main subject. The interview was scheduled for 30 minutes, according to the same considerations, the duration varied slightly from one subject to another.

\subsection{Data Collection}

Data collection was conducted in three phases. The first is an interview with the CT in order to have data that can be useful in this study as the number of years of experience and his career. At this meeting we presented to the teacher, the various stages of this research namely a video recording of the first meeting with the teacher followed by an interview semi directive representing the other two step of data collection.

\section{Result and Discussion}

\subsection{Result}

The contents of the speech of six CT during the welcome session, we conducted a coding after a didactic transcription. We developed six categories in which we have grouped the different types of advice: 1) "The behavior of PE-STs" whenever the CT talk about attendance, presentation and relationship to provide a model of the behavior of the CT. 2) "Documents and materials" whenever the CT states that the PE-STs must prepare a paper that contains essentially forms cyclic programming, instructional sheets, student assessment grids and observations between trainee teachers, have a notebook to keep track of absences, use of a notebook containing instructions on post sessions feedback and have a trousseau containing one or two whistles, a stopwatch, a double measuring tape, a watch. 3) "The organization" whenever CT talks about the management of infrastructure of the school and the equipment available, states that PE-STs must adapt to working conditions by sharing equipment with other teachers, pick up the equipment at the end of session so as not to lose, says to PE-STs must organize and control students. Make a disciplinary contract at the beginning of the school year and remind students of the rules disciplinary each session, impose disciplinary rules (to prohibit noise locker room, wearing jewelry, a mobile, the loss of its objects, tobacco, moving out of the classroom). They should not provoke or insult students, to not accept in case of successive delays. Punish them in a report, organize them into clubs and teaching level groups, accompany them to the locker room and the field. The PE-STs must manage the time of the session, advice the student to come on time and in uniform, not to waste time when dressing in the locker room, respect the time of the laying and does not release them late. The PE-STs must accountability agitated students, engage students in the organization of the session by transporting the materials and doing the markup ground, the observation and arbitration. 4) "The administrative tasks" whenever the CT states that PE-STs should making the call at the beginning and at the end of the session by noting and controlling. They should write in the call register with codes and track absentee and sick students throughout the cycles, talks about the different cases of the exclusion of the student, said that in case of accident, PE-STs must complete accident reports, talks about the different cases of the exclusion of the student. 5) "The interventions of PE-STs" whenever CT states that PE-STs must transmit knowledge, contribute to the regulation of the activity of students, have methods of intervention, and discover effective solutions to constraints. The PE-STs must use understandable 
language and do not make mistakes in pronunciation and no hesitation, listen to students. He must know the state of mind and problems of students at the beginning of the session, attract their attention, motivate and reward them to like the physical education field, ensure the security and health of students: no of intensive work. The CT says that PE-STs needs to student assessment; announce the results and the parameters taken into account in the note. Attribute the note and identify talent. 6) "The content taught" whenever the CT states that PE-STs must develop content to teach, programming situations by taking into consideration what the student loves their initial levels, the proofs of bac sport using game situations, the sport and physical activity program performed at training environment. Use knowledge disciplinary, doing documentary research, program from simple to complex. States that PE-ST must apply the objectives of physical education. ES should refer to the high program school. The PE-STs must develop theoretical lessons in bad weather. Every time the CT talks about student learning.

\subsection{Discussion}

The results reveal that the major concern of tutors seems to be the behavior of PE-STs (20.18\%) indicated in the Table 2: some of CT said: "I prefer that you arrive early, be at school at 7:30”, "each absence must be justified and signed by the ISSEP”, "Your outfit should be presentable” (CT 2).

"When I go to the administration, I want to hear good things about the student teachers. They are effective. I do not want to hear that they are an additional problem”, "we are here to give a good image of physical education. No one can speak and even if he talks, he will not say well of physical education. We, the physical education teachers, we need everyone respects us” (CT 5).

"Here, it has comments. This area is difficult; you have to taking precautions" (CT 4).

"About your relationship with the student, do not insult him or hit him or even touch. You should never call it with a nickname” (CT 2).

By referring to what is found in the literature, it could be said that this result is in accordance with all work of Levesque and Gervais (2000); Martineau (2000); Jorro (2007); Perez-Roux (2012) who spoke of the importance of the category "relationship" that occupies much of the volume advice interviews of CT. According to Martineau et al. (2010), the professional integration of teachers is a difficult time of life at work, during which the PE-ST is confronted with a multitude of experiences and new situations that must adapt quickly. Without support, it is very difficult for novice teachers to get through this crucial level of professional development. PerezRoux (2012) identifies ethical recognition that values interpersonal skills of the individual and the moral principles underlying them. These elements are essential for CT and PE-ST to operate. The sharing of values among professionals in the Council constitutes a form of recognition, a report to the profession that organizes their daily activities. Apart from the relational that articulates the self-esteem and the recognition of others, the biographical dimension implies for the individual to be recognized for what it is and for what he has experienced/constructed previously. Also, PE-SToften feel lost because they do not know the functioning of the school or the habits of teachers in place and must adapt to these innovations (Martineau, 2010). According to Martineau and Mukamurera (2012) to exercise a professional role in a given environment and be accepted as a member, it's essential that PE-ST appropriates operating rules, expectations and culture of this community. The introduction of PE-ST refers to the adaptation and mastery of the professional role by the development of knowledge and skills specific to this profession. This is the knowledge "teach the class", to become effective in the work according to professional skills expected. Ndoreraho and Martineau (2006) report that the difficulties experienced by PE-ST during their professional integration period such as stress in his functions and teaching in an unfavorable environment negatively affect their interest in applying the teaching profession. In the following, these difficulties are the cause of their profession abandonment.

The documentary and equipment has preparing (17.8\%) as indicated in the Table 2. One of them announced, “the pedagogy documentary are newspaper class, note book and notebook feedback” (CT 3).

The organization and control of the students (29.77\%) indicated in the Table 2 have the large proportion of Advice tutors. Some of CT said: "With a good organization, we will not find problems," "it's not for one person to take all the equipment, you have to share. You have to manage according to the available material” (CT 1).

"You have to do tracing and marking the field, you prepare yourself for the session." "You have to accustom students to be disciplined, presence at time, properly dressed”, "with discipline students can organize work for successful act of teaching” (CT 5). 
Table 2. Analysis grid of discourse of CTs during the introduce session.

\begin{tabular}{|c|c|c|c|}
\hline Category & The items & Total & $\%$ \\
\hline \multirow{4}{*}{$\begin{array}{c}\text { 1- The behavior of PE-ST } \\
\text { TOTAL: } 221 \\
20.18 \%\end{array}$} & Assiduity absence and lateness & 47 & 21.26 \\
\hline & presentation & 23 & 10.40 \\
\hline & Discipline, serious & 7 & 3.16 \\
\hline & Concentration & 26 & 11.76 \\
\hline \multirow{7}{*}{$\begin{array}{c}\text { 2- Documents and materials } \\
\text { TOTAL: } 195 \\
17.8 \%\end{array}$} & Relationship & 118 & 53.39 \\
\hline & & 221 & 20.18 \\
\hline & Preparation of the class journal & 148 & 75.89 \\
\hline & The workbook of the note & 10 & 5.12 \\
\hline & The notebook of feedback & 13 & 6.66 \\
\hline & Tool Kit of PE-ST & 24 & 12.3 \\
\hline & & 195 & 17.8 \\
\hline \multirow{5}{*}{$\begin{array}{l}\text { 3- The organization } \\
\text { TOTAL: } 326 \\
\text { 29.77\% }\end{array}$} & Management of resources & 89 & 27.3 \\
\hline & Spatial planning & 34 & 10.42 \\
\hline & Control of students & 124 & 38.03 \\
\hline & Time Management & 39 & 11.96 \\
\hline & Participation of students & 40 & 12.26 \\
\hline \multirow{5}{*}{$\begin{array}{c}\text { 4- The administrative tasks } \\
\text { TOTAL: } 99 \\
\text { 9.04\% }\end{array}$} & & 326 & 29.77 \\
\hline & Checking presence & 89 & 89.89 \\
\hline & Exclusion of the students & 6 & 6.06 \\
\hline & Filling the accident report & 4 & 4.04 \\
\hline & & 99 & 9.04 \\
\hline \multirow{4}{*}{$\begin{array}{c}\text { 5- The interventions of PE-ST } \\
\text { TOTAL: } 119 \\
10.86 \%\end{array}$} & Regulation of student activity & 60 & 50.42 \\
\hline & communication skills & 16 & 13.44 \\
\hline & Student motivation & 21 & 17.64 \\
\hline & Safety and health of students & 13 & 10.92 \\
\hline \multirow{8}{*}{$\begin{array}{l}\text { 6- The content taught } \\
\text { TOTAL: } 135 \\
12.32 \%\end{array}$} & Student assessment & 9 & 7.56 \\
\hline & & 119 & 10.86 \\
\hline & Choice of learning situations & 89 & 65.92 \\
\hline & Application of the aims of the EPS & 1 & 0.74 \\
\hline & Application of official programs & 7 & 5.18 \\
\hline & Conception of the theory lessons & 23 & 17.03 \\
\hline & Appropriations by students & 15 & 11.11 \\
\hline & & 135 & 12.32 \\
\hline Total: & & 1095 & \\
\hline
\end{tabular}

"The student must invest in the session and allows interest to physical education", "you can give it a responsibility, the student is going to help you" (CT 2).

By referring to the literature, it could be said that this result is in accordance with all work of Dugal and Amade-Escot (2004) that showed a predominance of class "organization" that occupies much of the volume advice interviews of CT.

The other part is constituted by the administrative tasks (9.04\%) indicated in the Table 2. Some of them have pronounced:

"The appeal is an administrative task; you must control the presence of students at the beginning and end of the meeting” (CT 1). 
“The Call Register, this document is a link between you, the administration and the parent. The administration needs to know that such a student is absent, present or late" (CT 3).

"If there is accident, fill out the false statement, filed with the administration to protect oneself and student" (CT 6).

The result obtained in research is in agreement with the work of Dugal (2003) concluded that the organizational concerns of classroom management most often take the priority over the content taught. In recent literature, Rayou and Ria (2009) found that some teachers were convinced that the work with minimal instructions helps to reduce noise and control of the class. According to Bremond (2013), the CT said they did not understand what they could bring to PE-STs who experiencing difficulties to control her students. Whereas the CTs consider that PE-STs was leaving an education that develops the management class. Martineau et al. (2010) and Bali (2015) argue that the lack of experience of beginning teachers makes it difficult to solve everyday problems particularly the classroom management. The CT spell out that the problems with the organization are the symptom of a particular difficulty to the PE-ST that should be questioned. These results are justified by Dugal (2003) who asserts that the CT spontaneously want to help and secure the PE-ST they have the charge to accompany; which is reflected by preoccupations oriented to the organization and the classroom management as to the content to be taught.

The interventions of PE-ST (10.86\%) indicated in the Table 2; One of them said: "the teacher is close to student, communication on the field or even way of speaking, that is to say in Arabic and French" (CT 2).

The content taught (12.32\%) indicated in the Table 2, the application of the purposes of the EPS and official programs (5.92\%) is second. One of CT said: "We will try to educate the student. Do not forget the purposes and programs of physical education" (CT 3).

Gervais and Desrosiers (2005) argue that tutor is an important component for teachers to implement in a real situation, what they learned during University studies. Boutet and Pharand (2008) add that student's teachers want to be guided and supervised. They want to take the initiative and accept that their errors are reported. Rayou and Ria (2009) argue that beginning teachers rarely have a clear awareness of the reasons for the failure or success in of their interventions.

The crossing of the content analysis of post sessions interviews and semi-structured interviews conducted with tutors brings us to clarify these results. The semi-structured interviews show that CT is more concerned with problems of organization and control students. They believe that teaching content is worth nothing without a good functioning of the class.

"I talked about the importance of discipline, more important than anything else. If students were undisciplined you could not do anything"

"You have to know how to organize and manage the classroom, how to choose the situations and program this is one will learn later" is the view expressed by (CT 3) in a semi structured interview.

According to Gervais and Desrosiers (2005), teacher training is undertaken by the school as a social responsibility. In a professional environment, the presence of PE-STs in education has high incidences on the daily work of the school staff, the executive team of the school teachers and non-teaching staff. They say they know little of the actual work of persons who introduce and accompany PE-STs to school as well as those who supervise them in the name of the training institution.

Gervais and Desrosiers (2005) report that the reasons to introduce PE-STs are of three types: professional development of PE-STs, in terms of opportunity for reflection, source of stimulation and satisfaction; the contribution to the renewal of the action in the classroom. Speaking of professional training, Gervais and Desrosiers (2005) propose to focus on the importance of naming the skills expected of PE-STs. They say that competence is constructed from a practice, in a real-professional context, is based on a set of personal resources (knowledge, skills, attitudes, other skills) and resources from the environment (colleagues, literature), develops gradually.

Carlier (2009) claims when the CTs describe their didactic and relational intervention, they are located in the three supervision style defined by Brûlé (1983). The democratic style (support, confrontation, discussion, clarification) the most used in the post sessions speech. Advice on the selection of content refers to the didactic style, the more directive (management, provocation, evaluation, security, education, demonstration). When the CTs adopt a posture of listening, they are in the non-directive experiential style (interpersonal exploration, consultation, self-expression, laissez-faire).

According to Mouton (2009) and Bali et al. (2014), the organization and conduct of the internship that sets up the CT, diced his first contact with the trainees, it will influence their conceptions and their appropriations. At 
the end to clarify their reciprocal expectations, Carlier (2002) suggest doing as a guide of training. CT is supposed to take the lead in drawing up the contract: "I, master your internship, what are my strengths, my characteristics? What I can honestly and modestly made, that you will not find elsewhere?” (Carlier, 2002: p. 103). The concept of didactic contract according Amade-Escot (2003) is central, as a concept focusing presupposed or implicit rules that organize the relationship teacher/students/knowledge. It is the anchoring point from which can be structured didactic observation. For its part, the didactic environment is the environment in which the student is and integrates equipment device, objects of knowledge or expertise, previous acquisitions and memory of the class.

Gervais and Desrosiers (2005) add that traineeships are an important component of any program of teacher training. They were provided in training to allow intending PE-STs to implement in a real situation, what they had learned at university. Both authors spoke of the link between theory and practice, postulating that the theoretical knowledge was acquired outside school and that the contribution of the school was limited to the practical dimension. The internships also aimed at allowing to PE-STs to demonstrate their level of mastery of skills deemed essential for teaching. They add that in the current training programs, internships are rather approached as experiments to gain a realistic picture of the working environment and profession, develop progressively of professional skills by mobilizing various resources, including knowledge acquired in academia. The internship is a learning environment of multiple knowledge and fostering the awareness's and identification of requirements for knowledge.

Carlier (2009) shows that CTs are based on the most accessible resources to construct their profession. They refer primarily on their personal experience of teachers. According to Bremond (2013) and Bali et al. (2014), the training is approached as an interaction, the CT is an actor among others; it's not a holder of knowledge. The diffusion of knowledge is fundamentally tainted by the exchange in which she will set out. The CT aims is to transmit knowledge and not talking. He must register in the interaction without forgetting the unexpected and indefinite nature of professional situations they exchange.

In this approach, Leriche et al. (2010) and Bali et al. (2014) believe that internships are not sufficient to promote the development of professional teaching skills. The success of this company seems strongly associated with accompanying practices implemented by the CT. They postulate that the PE-ST is the central actor in his own training. It is not isolated with a CT, but surrounded by teachers, including other CT, in contact with members of the school including the school administration, with students and other trainees. The role of the CT is paramount in accompanying the PE-ST, but a large number of actors participating, formally or informally, for his training. In this orientation, Perrenoud (1994) argues that teaching is a profession that requires great flexibility, a practice engaged in uncertainty, where various dimensions of human relationships coexist.

Boutin and Camaraire (2001) state that if the criteria for selection of CTs based on the pole model (teaching experience, proven expertise, team spirit and sensitivity to the life of the school), the pole trainer of CT remains high (observation skills, analytical and critical thinking). Boutet (2002) lists some characteristics of a good CT: the experience, the confidence in its means, the openness to theoretical contributions and reflection, the coherence, the acceptance to question and to be questioned. To be a CT, one must be able to explain his thinking; to work in teams and to share tasks also have interpersonal skills, attention to each other and positive confrontation. For its part, Gosselin (2002) proposes various conceptions of what constitutes a CT. It uses six poles of Lang (1999) to represent these tendencies: the academic pole (an educated master who knows his subject); artisanal pole (the CT craftsman imitated by the apprentice observing); the pole of Applied Science and Technology (the emphasis is on the "how, knowledge in the laboratory); personality pole (the quality of the relationship, psychological maturity of the CT, the development of his own style of teaching); the pole of the social actor (the effort to develop critical thinking); professional pole (the reflective practitioner able to analyze what he does in terms of the effects produced) Bali (2013).

Trohel et al. (2004) described the forms of joint commitments of the CT and the PE-ST during their interaction during post-lesson interviews, giving a privileged viewpoint of each actor involved in these interactions. They noticed that the CT is not or poorly trained in the role of tutor, they act on the basis of their professional experience and competence to teach physical education. Recent studies Beau-Antony and all (2011) are moving in this direction, they study the characteristics of the professional activity of the CT to identify the difficulties encountered when supervising PE-ST. They showed that tutoring is a difficult function to perform because you have to engage the best in a mission for which most of the time it's poorly trained.

Boutin and Camaraire (2001) developed a guide for teachers who introduce the PE-STs. It notes the qualities 
required to their accompaniment: altruism, maturity, experience and communication skills, a willingness to share and to make discover. To play the role of a CT, the tutor should possess specific skills (Boudreau, 2009). According to Carlier (2002), the CT must have a style; develop a training contract, the mastery of interview techniques and the evaluation. Carlier (2002) proposes to bring the CT and PE-ST to exchange about academic knowledge and knowledge. Avoid introducing his trainee so: "Forget everything you learned in college" Carlier (2002: p. 104). Carlier (2002) suggests to CT to recognize the existence of two types of knowledge and try to exploit them optimally. It presents two distinct worlds that everything seems to separate: the academic world on the one hand and professional reality, on the other. In addition, Carlier (2002) proposed to establish a communications contract with the trainee to guide the verbalization of his action. Through questioning that he put in place, the CT enters the psychic intimacy of the trainee.

Finally, Carlier (2002) wants the CT course could: first, increase the self-confidence of the PE-ST by allowing them to appropriate the content and models of appropriate behavior to interactive classroom management. Secondly, bring the PE-ST to analyze and evaluate his practice by directing it to the methods that allow for crossing the barrier between the experience and the experiential knowledge.

According to Faingold (2006) the most positive points in professional training are the quality of discussions, debates and the sincerity of the relationship between PE-ST and the CT. From session to session, this work makes sense and interest: listening quality and type of questions. It take distance from its practice promotes the sharing of experiences and modifies representations of the profession (students accept them as they are to be active and daring to express in his establishment; dialogue and work with colleagues).

Faingold (2006) suggests promoting the speaking the PE-ST, refraining from interfering to better listen and understanding his views on his practice. The CT should change posture. It must cease to be in a position to pass on knowledge to become accompanist appropriating a style intervention, assistance and conceptualization of experience.

Bali et al. (2014) confirm the difficulties encountered by the trainee teacher influences these behaviors and the tutor takes by responsibility see its role to clarify the objectives of the training.

It demonstrates the need for reflection on how the integration of PE-ST in schools in the hope of finding solutions to the con-constraints imposed on them in their professional environment. This requires reflection on the competence and CP response.

Escot (2004) questioned the impact of counseling on the didactic and the place given to the content taught. For this, three main categories were developed: the organization, the interventions with students and the content taught. Results of these studies show a predominance of class "organization" that takes up half the volume interviews advice of CT, the other half consisting of two other categories ("interventions for students" and "the content taught”). Mouton (2009) confirms that the nature of the counseling of and its contents depend on the environment co-constructed by the CT and PE-STs but also from the conception of the CT to introduce PE-ST into the profession.

Mouton (2009) finds that there is a great illusion to believe that CT is able to respond effectively to the requirements of a trainee engaged with a problem situation. He added that the CT is neither a scientist nor an expert, but a professional who organizes a training environment in a role to introduce PE-STs in the teaching profession.

Bremond (2013) suggests CT to reintroduce the dimension of the relationship with knowledge and position themselves active subject not just a catalyst. He asked the CTs to occupy a role that determines the exchange rather than the absolute neutrality.

According to Carlier (2009) the CTs extract from their practice the best knowledge of experience to make them available to the PE-STs in the profession they exercise. This expression of personal theories (Donnay and Charlier, 1996) is a first step in a reflexive approach, which is essential to the professionalization of the CT.

Vandercleyen et al. (2013) and Bali (2015) show that the success of the professional training depends largely on the type of intervention of the CT to the PE-ST, and the quality of the relationship between the two actors. They highlight in particular the dual role of the CT, to be able to explain their own pedagogical concepts to the PE-ST and help the latter to clarify his thoughts, his actions and his decisions.

Loizon (2008) reveals that counseling training must become a priority for all who are led to "give advice", or rather "hold advice" (Dugal, 2006). Loizon (2008) showed that training through research contributes to the development of the skills of counselors. To produce effects, training of CT must register in time and in confidence. These are the two major conditions that have allowed advisers say and write their feelings, their doubts, their 
remarks; this engagement in a real research work produced declared transformations and questioning of their consulting practices. The training generate a new question: "I give direct advice, but what effect does it have?"

\section{Conclusion}

The study of the accompanying practices of six CTs in two secondary schools practices, responding to a question: how CT introduces PE-ST into teaching practices through the first discourses post-sessions.

Globally the concerns of the tutors revolve around the acquisition of six professional skills that PE-ST should be used in the exercise of his profession: 1) acting in an ethical and responsible, 2) cooperate with school staff, parents, 3) working with members of the teaching staff, 4) communicate clearly and correctly in the teaching language, oral and written, 5) conceive teaching and learning situations, 6) control of teaching situations.

At the beginning of year, we found that the discourse of CT is more oriented to the professional identity and the school context that the act of teaching. For tutors, a PE-ST should be well behaved, prepared these documents, organizing his students accomplish administrative tasks, how to intervene and develop content to teach. These interpretations raise the question on the contribution of the Council to provide education, and the place given to the conception of the content taught and their appropriation by the student.

An important question that emerges from this study: Namely the evolution of councils of the CT in the professional training. We will discuss in the next article.

\section{References}

Amade-Escot, Ch. (2003). Interactive Management of Didactic Contract in Volleyball. In C. Amade-Escot (Ed.), Teaching of Physical Education: State of Research (pp. 255-278). Paris: EPS Review.

Amade-Escot, Ch. (2004). Study the Work of the Physical Education Teacher in the Classroom: Teaching Contribution to the Research Analysis of Actual Practices. In J.-F. Marcel (Ed.), Practice Teachers outside the Classroom (pp. 53-77). Paris: L'Harmattan.

Bali, N., et al. (2014). The Conceptions of Integration of Tunisian Physical Education Cooperative Teachers and Student Teachers. Creative Education, 5, 279-289. http://dx.doi.org/10.4236/ce.2014.54037

Bali, N. (2013). Teachers’ Thought Processes: The Case of Tunisian Gymnastic University Teachers. Creative Education, 4 , 77-84. http://dx.doi.org/10.4236/ce.2013.47A2020

Bali, N. (2015). The Tunisians Cooperative Teachers and Student Teachers' Conceptions about Class Management Skill. Creative Education, 6, 87-99. http://dx.doi.org/10.4236/ce.2015.61008

Bali, N., et al. (2012). The Conceptions of Authority of Tunisian Physical Education Cooperative Teachers and Student Teachers. Conference Proceedings of the 7th Biennial ARIS, Amiens.

Boudreau, P. (2009). For a Model of Supervision of Inductive Training in Supervising Tutors in Physical Education. Education and Francophonie, 1, 37.

Boutet, M., \& Pharand, J. (2008). Concentrated Accompanying of Student Teachers. Quebec: PUQ.

Boutet, M., \& Rousseau, N. (2002). The Challenges of Teaching Practicum Supervision. Quebec: PUQ.

Boutin, G., \& Camaraire, L. (2001). Introduce and Mentor of Student Teacher. Practical Guide for Teacher-Trainer, Montreal, News Editions.

Brau-Antony, S., Mieusset, C., Lenfant, A., \& Miot, C. (2011). Analyze the Work of Tutors Beginning Teachers. Continuing Education, 186, 175-185.

Bremond, C. (2013). The Trainer He Knows What He’s Talking. New Review of Psychology, 1, 241-252.

Carlier, G. (2002). Supervise of Trainee in Physical Education: Tags for a Function in the Process of Professionalization. Louvain: Catholic University of Louvain, 96-111.

Carlier, G. (2009). Accompany and Training of Tutors in Physical Education. The Experience of the Catholic University of Louvain (Belgium). Education and Francophonie, 37, 68-88. http://dx.doi.org/10.7202/037653ar

Carlier, G., \& Clerx, M. (2012). The Pleasure of Participating in Continuing Education Training. In: G. Carlier, C. Borges, M. Clerx, \& C. Delens (Eds.), Professional Identity in Physical Education: Research in Teacher Education and Teaching (pp. 23-41). Leuven: Leuven University Press.

Crinon, J. (2003). Professional Teacher's Memory Observatory Practices and Leverage for Training. Harmattan.

Darnis, F., \& Magendie, E. (2011). Teacher Training in Alternation: Towards the Co-Construction of Pragmatic Concepts. Knowledge Magazine, 27, 63-83. 
Desbiens, J. F., Borges, C., \& Spallanzani, C. (2009). Educational Supervision in Physical Education. Education and Francophonie, 37, 1-5.

Dugal, J. P. (2003). Consulting Initial Teacher Training: Interest and the Pedagogic Knowledge for Mentoring Student Teachers in EPS. Doctoral Dissertation, PhD in Sports Science, Toulouse: Université Toulouse III-Paul Sabatier.

Dugal, J. P., \& Amade-Escot, C. (2004). Consulting Initial Teacher Training: Interest and the Pedagogic Knowledge for Mentoring Student Teachers in EPS. Doctoral Dissertation, PhD in Sports Science, Toulouse: Université Toulouse III-Paul Sabatier.

Faingold, N. (2006). Training of Trainers in the Analysis of Practices. Research and Education, 51, 89-104.

Gervais, C., \& Desrosiers, P. (2005). The School, Place of Teaching Training: Question and Marks and for Supervision of Trainees. Canada: The Laval University Press.

Jorro, A. (2007). The Alternation Research and Professional Training Ground. Research and Training, 54, 101-114.

Leriche, J., Desbiens, J. F., Dugal, J. P., \& Amade-Escot, C. (2010). Analysis of the Accompanying Responsibility in Quebec and France: A Look at the Post-Lesson Interviews with the Ecology of the Classroom. Review e-JRIEPS, 71-98.

Lévesque, M., \& Gervais, C. (2000). Professional Integration: A Step to Succeed in the Professionalization of Teaching. Education Canada, 40, 12-15.

Loizon, D. (2008). Training of Educational Adviser’s First Degree by Research. Research and Education, 59, 105-119.

Maela, P. (2009). Around the Word Accompaniment. Research and Training, 62, 91-107.

Martineau, S., \& Corriveau, G. (2000). Promoting an Understanding of the Sense of Professional Incompetence among Teachers in Secondary Vocational Integration. Training and Profession, 6, 5-8.

Martineau, S., \& Mukamurera, J. (2012). Overview of Major Programs and Support Systems for Professional Integration in Education. Phronesis, 1, 45-62. http://dx.doi.org/10.7202/1009059ar

Martineau, S., \& Presseau, A. (2003). The Sense of Professional Incompetence of Teachers Early in Their Careers and Support Employability. Brock Education, 12, 2-6.

Martineau, S., Portelance, L., \& Presseau, A. (2010). Mentoring as a Support System for the Employment of Teachers. Proceedings of the International Conference on Complex Thinking: Challenges and Opportunities for Education, Research and Organizations, 31, 2-8

Mouton, J. C. (2009). Form Analysis Consultancy Master Trainer Training of Accompanied Practice. Research and Education, 62, 65-76.

Ndoreraho, J. P., \& Martineau, S. (2006). A Problematic Beginning of the Teaching Career. Retrieved November $20,2009$.

Perez-Roux, T. (2012). Identity Construction of New Teachers: What Recognition of Others to (Re) Known as a Professional? Educations \& Research Journal, 7, 69-84.

Perrenoud, P. (1994). Teacher Training: Theory and Practice. Paris: L’Harmattan.

Rayou, P., \& Ria, L. (2009). Train New Teachers. Various Statutes, Organization and Professional Knowledge. Education and corporate, 1, 79-90.

Trohel, J., et al. (2004). The Dynamic of Interactions Tutors Students Experiencing Educational Advice. Knowledge, 5, $119-140$

Vandercleyen, F., Delens, C., \& Carlier, G. (2013). Supervision Styles of Tutors in Physical Education: Consideration of the Emotional Experiences of Trainees during a Post-Lesson Interview. EJRIEPS, 61-99. 